\title{
Thermophilic Co-Digestion of Sewage Sludge and Brewery Spent Grain
}

\author{
Magdalena Lebiocka ${ }^{1 *}$, Agnieszka Montusiewicz' ${ }^{1}$ Aleksandra Szaja' ${ }^{1}$ \\ Sylwia Rembisz', Ewelina Nowakowska' \\ 1 Lublin University of Technology, Faculty of Environmental Engineering, ul. Nadbystrzycka 40 B, \\ 20-618 Lublin, Poland \\ * Corresponding author's e-mail:m.lebiocka@pollub.pl
}

\begin{abstract}
This study examined the effectiveness of thermophilic co-digestion of sewage sludge and milled/non-milled brewery spent grain. The experiments were performed in batch-mode to evaluate both the biogas potential and the biogas production rate. Five runs were carried out, one of them concerned the anaerobic digestion of sewage sludge (as control), whereas the others referred to the co-digestion of sewage sludge with addition of milled and nonmilled brewery spent grain at doses of 5 and $10 \mathrm{~g}$. The runs were conducted under thermophilic conditions (temperature $55 \pm 1{ }^{\circ} \mathrm{C}$ ) and lasted for 21 days. The effectiveness of the process was assessed on the basis of the volatile solids removal, biogas potential and the rate of biogas production. The physiochemical composition of reactor feed and digestate were characterized. The addition of the brewery spent grain resulted in increase of the biogas potential, but a decrease in the volatile solids removal. In the case of biogas production rate, the highest value was recorded in the run with the addition of $10 \mathrm{~g}$ of milled and non-milled brewery spent grain $\left(0.69 \mathrm{Ndm}^{3} \mathrm{dm}^{-3} \mathrm{~d}^{-1}\right)$. There was no observed influence of milling on the thermophilic co-digestion effectiveness since the parameters specified revealed comparable values.
\end{abstract}

Keywords: anaerobic digestion, co-digestion, brewery spent grain, pre-treatment, milling

\section{INTRODUCTION}

The brewing industry generates relatively large amounts of by-products and wastes, such as brewery spent grain (BSG), spent hops and yeast. Brewery spent grain contains about $16.8-25.4 \%$ cellulose, $21.8-28.4 \%$ hemicellulose (mostly arabinoxylans) and $11.9-27.8 \%$ of lignin (Santos et al. 2003, Mussato et al. 2006). The major part of BSG constitute the kernel husk, pericarp and seed coat, which are rich in cellulose, non-cellulosic polysaccharides, lignin and also some proteins and lipids. In general, BSG is considered as a lignocellulosic material rich in fibers and proteins, which account for about $70 \%$ and $20 \%$ of its composition, respectively (Outeiriño et al. 2019, Ravindran et al. 2018). Utilization of these byproducts in a form of animal fodder or compost is well-known. However, with increasing energy costs, the brewing industry, which consumes approximately $4 \mathrm{~m}^{3}$ of natural gas per hectolitre of beer, strives to convert most of its wastes to alternative energy sources. In such perspective, anaerobic digestion has become an alternative for the production of renewable energy through biogas from these waste substrates. The anaerobic digestion of brewer's grain has been studied in the literature. Brewery spent grain is a substrate consisting largely of cellulose, hemicellulose and lignin, which are difficult to degrade anaerobically, mostly due to the presence of degradation products, such as phenolic compounds, which cause the process inhibition (Panjičko et al. 2017). According to Sežun et al. (2011), BSG as a mono substrate cannot be anaerobically digested in a semi-continuous bioreactor under mesophilic conditions, regardless of its pretreatment. A significant inhibition of the biogas production 
occurred, depending on the type of substrate pretreatment. The biogas production from BSG as a potential lignocellulosic substrate was inhibited by intermediate lignocellulosic biodegradation products, $\mathrm{p}$-cresol being the most responsible. The structural complexity of lignin, its high molecular weight, chemical stability and insolubility make the biodegradation of this lignocellulosic substrate quite difficult. The lignocellulosic biomass has improper nutrient structure, high organic load, deficiency of diversified microbes and low nitrogen content; all these factors are the potential inhibitors for the AD process. High $\mathrm{C} / \mathrm{N}$ ratio, lignin percentage and contamination with pesticides influenced the process dynamics. Most of these kinds of problems are resolved by the addition of co-substrate in the reactor, and this process is called as anaerobic co-digestion (AcoD) (Kainthola et al. 2019). A good strategy to improve the biomethanization process of lignocellulosic wastes is the AcoD but their pretreatment is also a feasible option (Diego-Diaz et al. 2019). The effective utilisation of BSG for valorization requires the techniques to disrupt the naturally ordered structure and remove lignin (Niemi et al. 2012, Madison et al. 2017). Pretreatment methods are essential in increasing the efficiency of the processes that involve the valorization of lignocellulosic materials. With respect to the mechanism behind the process, they can broadly be classified into physical, chemical, biological, thermal and combinational methods. An efficient pretreatment strategy essentially should be simple, cost effective, devoid of corrosive materials and should not give rise to indigestible or inhibitory compounds. Mechanical size reduction during milling is a crucial step for the transformation of feedstock into energy (Rodriguez et al. 2017; Montusiewicz and Pawłowska 2017). In most papers in literature, biomass fragmentation during milling is applied as a first pretreatment step. However, the availability of information concerning process parameters and energy balances is low. It is generally stated that the concentrations of biomethane, bioethanol and biohydrogen are approximately 5-25\% greater for fragmented biomass compared to non-fragmented structures (Hendriks et al. 2009, Kucharska et al. 2018). The study examined the effects of co-digestion of brewery spent grain and sewage sludge under thermophilic conditions. The experiments were performed in batch-mode to evaluate both the biogas potential and the biogas production rate.

\section{MATERIAL AND METHODS}

\section{Material characteristics}

Mixtures of sewage sludge and dried brewery spent grain (both non-milled and milled) were used for the co-digestion study. The sewage sludge was used for the anaerobic digestion as a control. The sewage sludge was obtained from the Lublin municipal wastewater treatment plant (WWTP), Poland. This included two-source residues from primary and secondary clarifiers, both of them thickened. Under laboratory conditions, the sludge was mixed at the recommended volume ratio of 60:40 (primary : waste sludge), then homogenized, manually screened through a 3 -mm screen and partitioned. The sludge prepared in this manner was fed to the reactor as mixed sewage sludge (SS), with main characteristics presented in Table 1. Brewery spent grain (BSG) was sourced from a small brewery in Lublin that uses barley as a raw material for beer production. The BSG sample of $2 \mathrm{~kg}$ weight was transported to the laboratory, then dried using an oven at a temperature of $50^{\circ} \mathrm{C}$ to omit its rapid degradation and sub-divided. One of the sub-samples was milled using a stainless steel blender to reduce the BSG particle size to $1 \mathrm{~mm}$ (MBSG), the other was retained without milling. The BSG composition is given in Table 1. An inoculum for the laboratory reactors was sampled from Lublin WWTP as a digest collected from a mesophilic anaerobic digester operating at a hydraulic retention time of about 30 days.

At the beginning of the experiment, each reactor was inoculated with the digest from Lublin WWTP. Before starting the anaerobic digestion, the nitrogen gas was purged for $2 \mathrm{~min}$ in each reactor to remove the gases present inside and ensure anaerobic conditions. After 30 days of adaptation ensuring the inoculum to be deeply treated with residual daily biogas production of $0.01 \mathrm{Ndm}^{3} \mathrm{~d}^{-1}$, the reactors were fed with the substrates and washed out once again using nitrogen gas.

Table 1. Characteristics of co-digestion components during experiment (average values \pm standard deviation)

\begin{tabular}{|c|c|c|c|}
\hline Parameter & Unit & $\begin{array}{c}\text { Mixed sewage } \\
\text { sludge }\end{array}$ & $\begin{array}{c}\text { Brewery Spent } \\
\text { Grain }\end{array}$ \\
\hline TS & $\mathrm{g} \mathrm{kg}^{-1}$ & $46.25 \pm 0.62$ & $223.9 \pm 4.3$ \\
\hline $\mathrm{VS}$ & $\mathrm{g} \mathrm{kg}^{-1}$ & $34.56 \pm 0.24$ & $217.2 \pm 4.2$ \\
\hline $\mathrm{pH}$ & - & $6.62 \pm 0.01$ & - \\
\hline
\end{tabular}




\section{Laboratory installation and operational set-up}

The specific biogas (BP) and methane potential (BMP) of inoculum, sewage sludge and codigestion mixtures were studied in batch assays using the automatic biogas/methane potential test system BioReactor Simulator (Bioprocess Control AB, Sweden). The BRS consisted of two units: BRS-A and BRS-B (Fig. 1).

The BRS-A unit comprised of 6 reactors with the volume of $2 \mathrm{~L}$. The media in each reactor were mixed by means of a slowly rotating agitator. Biogas was continuously produced and registered by the system. The volume of the gas released was measured with unit BRS-B using a wet gas flow-measuring device with a multi-flow cell arrangement, which works according to the principle of liquid displacement and can monitor low gas flows (a digital pulse is generated when a defined volume of gas flows through the device). An integrated embedded data acquisition system was used to record and display the results. After the adaptation of inoculum which lasted 30 days, six runs were carried out. The BP tests were conducted in duplicates, under mesophilic conditions (at a temperature of $55 \pm 1^{\circ} \mathrm{C}$ ). Each of these lasted 21 days. The reactors were fed using mixture of SS and milled/non-milled BSG (the influent consisted of a mixture of $1.4 \mathrm{~L}$ inoculum, $0.4 \mathrm{~L} \mathrm{SS}$ and selected dose of milled/non-milled BSG). The influent of first run consisted of a mixture of 1.4 L inoculum, 0.4 L SS. The second and third run arrangement was the same as the previous one, but this time the influent consisted of a mixture of $1.4 \mathrm{~L}$ inoculum, $0.4 \mathrm{~L} \mathrm{SS}$ and 5 and $10 \mathrm{~g}$ MBSG for R2 and R3, respectively. The other

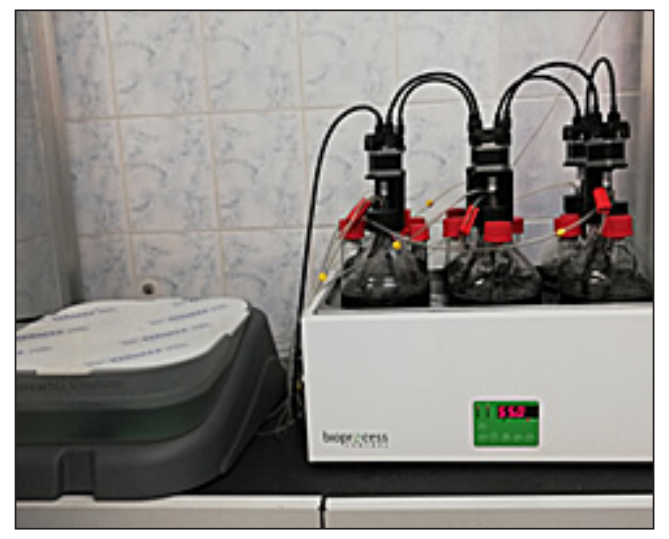

Fig. 1. BioReactor Simulator (BRS): anaerobic reactors (BRS-A, unit in the right), gas volume measuring device (BRS-B, unit in the left) runs (R4-R5) were fed with $1.4 \mathrm{~L}$ of inoculum, $0.4 \mathrm{~L}$ of a mixed sludge and non-milled BSG at a rate of 5, $10 \mathrm{~g}$ for the $\mathrm{R} 4$ and $\mathrm{R} 5$ reactors. The biogas produced by the inoculum was subtracted from the results obtained from the test samples. The biogas (BP21) and methane (BMP21) potential as well as the biogas (GPR) and methane production rate (MPR) were determined.

\section{Analytical methods}

In the samples of SS and BSG, total solids (TS), volatile solids (VS) and $\mathrm{pH}$ were analyzed in triplicates. Total solids were determined as the residue after water evaporation (24 h drying at $105^{\circ} \mathrm{C}$ to constant weight), volatile solids were measured by ignition at $500^{\circ} \mathrm{C}$. TS and VS were determined according to Polish Standards Methods PN-75/C-04616/01, pH were analyzed according to PN-EN 12176. The biogas volume was measured on-line using BRS-B unit. The composition of the biogas was measured using a Shimadzu GC 14B gas chromatograph coupled with a thermal conductivity detector (TCD) fitted with glass packed columns. The Porapak Q column was used to determine the $\mathrm{CH}_{4}$ and $\mathrm{CO}_{2}$ concentrations. The parameters used for the analysis were as follows - injector $40^{\circ} \mathrm{C}$, column oven $40^{\circ} \mathrm{C}$, detector $60^{\circ} \mathrm{C}$, and current bridge $150 \mathrm{~mA}$. The carrier gas was helium with a flux rate of $40 \mathrm{~cm}^{3} \mathrm{~min}^{-1}$. The peak areas were determined by the computer integration program (CHROMAX).

\section{RESULTS AND DISCUSSION}

\section{influent characteristics and operational conditions during experiment}

The characteristics of the influent that supplied the reactor in R1-R5 runs are presented in Fig. 2, (the left bars). In order to clarify the digestion results, effluent characteristics was also compiled on the same figures.

It should be noted that the $\mathrm{pH}$ value in the influent was at a comparable level for all runs and averaged 6.60. The analysis of the composition of the influent used in the experiments indicated that the average TS and VS increased as the BSG dose increased (Fig. 2). A clear tendency appeared with regard to the addition of both milled and non-milled brewery spent grain. The experimental results of Wang et al. (2016) showed that the 
a)

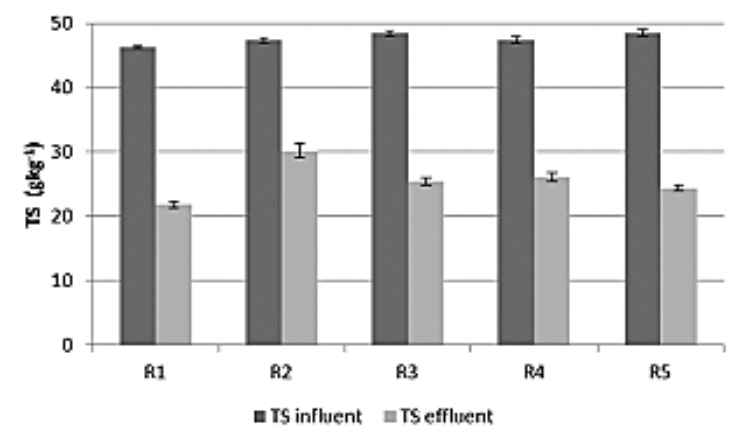

b)

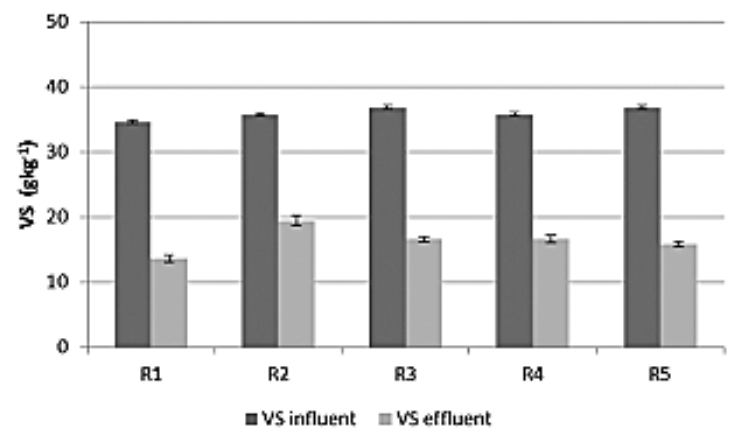

Fig. 2. Influent and effluent characteristics for successive runs: a) TS b) VS

production of biogas increased along with the ratio of VS/TS in the feedstock. In this case, the lowest value of the VS:TS ratio of 0.747 was obtained in the case of sewage sludge suppling R1 (control run). The value of VS:TS ratio increased along with the BSG dose. Brewer's spent grain milling had no effect on the value of the VS:TS ratio. The value of VS:TS ratio was 0.753 for R2 and R4 and 0.759 for R3 and R5. The higher VS:TS ratio in co-fermentation runs indicates a much higher content of organic compounds as compared to the anaerobic digestion of sewage sludge. The degree of removal pertaining to VS was used to evaluate the process efficiency. On average, the removal efficiencies of VS in R2, R3, R4 and R5 (the reactors with BSG addition) amounted to $45 \%, 55 \%$, $53 \%$ and $57 \%$, respectively. These values were lower than the ones obtained for sewage sludge $(61 \%)$. The lower values of removal efficiency of VS in R2-R5 runs may be due to insufficient hydraulic retention time needed for the decomposition of lignocellulosic matter, even under thermophilic conditions or due to the possibility of release of phenolic compounds inhibiting the co-fermentation process.

\section{Biogas production}

In Europe, the method of biogas production for 21 days $\left(\mathrm{BP}_{21}\right)$ is applied as a standardized test for the assessment of biogas production rate of various kinds of substrates. The results of the study concerning the biogas/methane potential and the biogas/methane production rate are given in Table 2. The cumulative biogas production obtained for each run is presented in Fig.3. The data on the graph represent the average values of daily biogas production per $\mathrm{g}$ of VS fed the reactors for the specified runs.

Concerning the addition of BSG and MBSG, all the co-digestion parameters increased as compared to the control run. The highest biogas potential was obtained for the SS $+10 \mathrm{~g} \mathrm{MBSG}$ and $\mathrm{SS}+10 \mathrm{~g} \mathrm{BSG}$ (R3 and R5) samples. This was higher by $16.9 \%$ compared to $\mathrm{SS}+5 \mathrm{~g} \mathrm{MBSG}$ (R2), 21.1\% compared to addition of $5 \mathrm{~g}$ of BSG (R4) and 53.3\% higher than the control run (R1). With the increase in the dose of co-substrate, the value of biogas potential grew as well. The methane concentration was a little lower in the presence of brewery spent grain and ranged from $68.03 \% \pm 0.49$ to $68.61 \% \pm 0.45$. In the case of SS, it was $70.05 \% \pm 0.49$. According to Siqueiros et al. (2019) the biogas potential for brewery waste (90\% grains and about $10 \%$ of hops and yeast) undergoing anaerobic digestion under thermophilic conditions amounted $0.5 \mathrm{dm}^{3} \mathrm{~g}^{-1} \mathrm{VS}$, methane content was about $65 \%$. Interestingly, there was no observed influence of milling on the co-digestion effectiveness since the parameters

Table 2. The biogas/methane potential and production rate during experiment (the average value and standard deviation are given)

\begin{tabular}{|c|c|c|c|c|c|c|}
\hline Parameter & Unit & $\begin{array}{l}\text { R1 } \\
\text { SS }\end{array}$ & $\begin{array}{c}\text { R2 } \\
S S+5 g \text { MBSG }\end{array}$ & $\begin{array}{c}\mathrm{R} 3 \\
\mathrm{SS}+10 \mathrm{~g} \mathrm{MBSG}\end{array}$ & $\begin{array}{c}\text { R4 } \\
S S+5 g \text { BSG }\end{array}$ & $\begin{array}{c}\text { R5 } \\
S S+10 \mathrm{~g} B \mathrm{G}\end{array}$ \\
\hline $\mathrm{BP}_{21}$ & $\mathrm{Ndm}^{3} \mathrm{~g}^{-1} \mathrm{VS}$ & $0.45 \pm 0.02$ & $0.59 \pm 0.021$ & $0.69 \pm 0.026$ & $0.57 \pm 0.043$ & $0.69 \pm 0.031$ \\
\hline GPR & $\mathrm{Ndm}^{3} \mathrm{dm}^{-3} \mathrm{~d}^{-1}$ & $0.75 \pm 0.024$ & $1.01 \pm 0.054$ & $1.21 \pm 0.059$ & $0.97 \pm 0.049$ & $1.21 \pm 0.061$ \\
\hline $\mathrm{BMP}_{21}$ & $\mathrm{Ndm}^{3} \mathrm{~g}^{-1} \mathrm{VS}$ & $0.31 \pm 0.017$ & $0.40 \pm 0.032$ & $0.47 \pm 0.023$ & $0.39 \pm 0.032$ & $0.47 \pm 0.025$ \\
\hline MPR & $\mathrm{Ndm}^{3} \mathrm{dm}^{-3} \mathrm{~d}^{-1}$ & $0.53 \pm 0.015$ & $0.69 \pm 0.028$ & $0.83 \pm 0.029$ & $0.67 \pm 0.027$ & $0.82 \pm 0.030$ \\
\hline
\end{tabular}



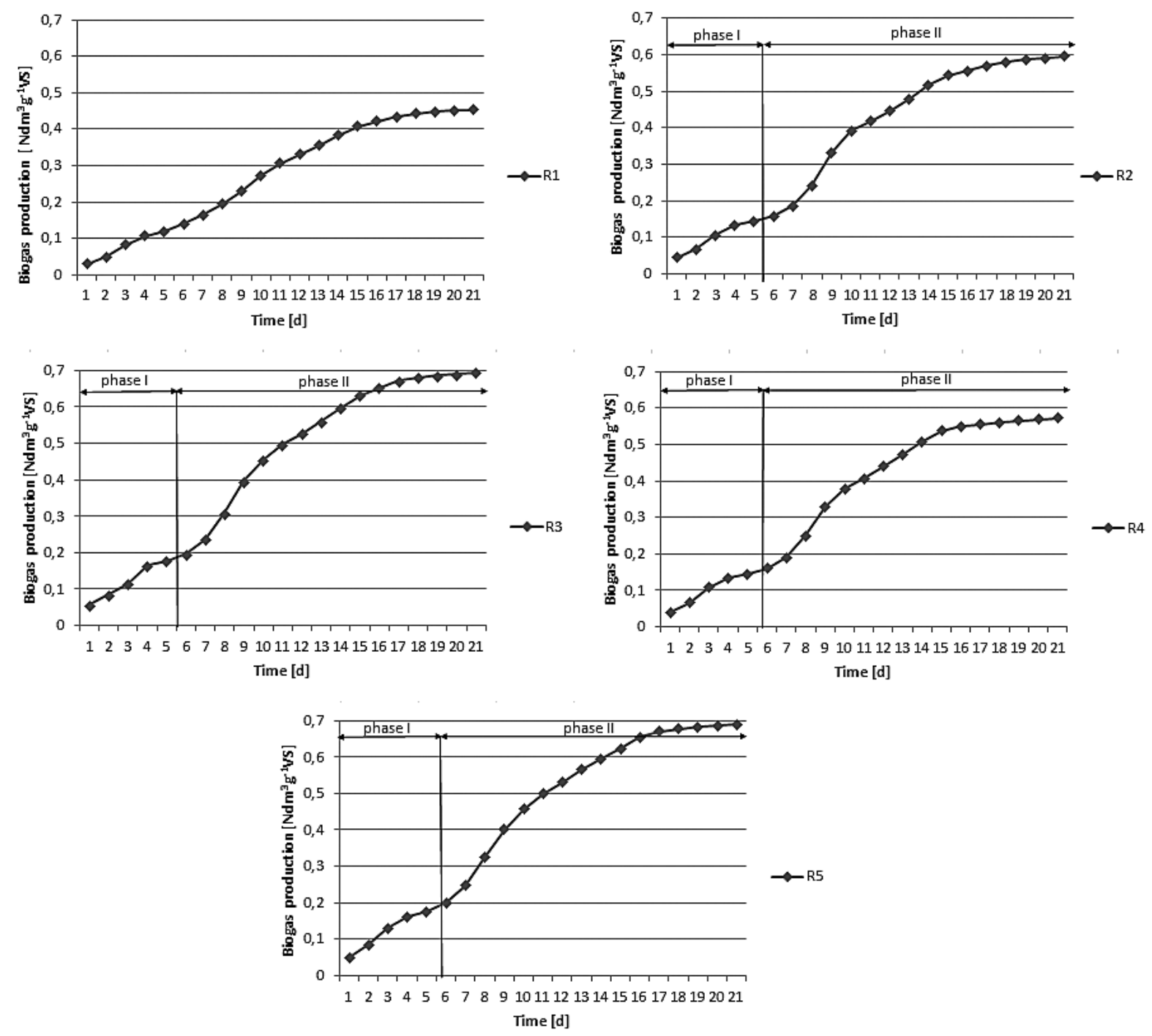

Fig. 3. Cumulative biogas production for specified runs

specified revealed comparable values. Thus, adding both BSG and MBSG in dose of $5 \mathrm{~g}$ and $10 \mathrm{~g}$ did not alter the co-digestion results. Temperature is one of the most influential parameters which affect the performance and stability of anaerobic digestion. Working under thermophilic conditions $\left(55^{\circ} \mathrm{C}\right)$ can enhance the performance of anaerobic digestion because of higher solubility of organic compounds, higher chemical and biochemical reaction rates, lower solubility of gas in the liquid, lower liquid viscosity, higher pathogen deactivation and lesser odor emission. On the contrary, higher temperatures increase the inhibitory effect of ammonia and VFA (Angelidaki and Ahring 1993, Neshat et al. 2017). The anaerobic digestion of sewage sludge and BSG under mesophilic conditions was also studied by the authors (Lebiocka et al. 2018). Addition of brewery spent grain in the dose of $5 \mathrm{~g}$ (milled and non-milled BSG) increased the biogas potential by $19 \%$, while the biogas production rate was over $27 \%$, as compared to the control. The use of a higher (thermophilic) process temperature resulted in higher biogas potential values and gas production rate.

The cumulative biogas production was differentiated for the co-digestion and control runs. Figure 3 depicts cumulative biogas production curves over 21 days of the experiment. In the case of SS, the curve increases and follows the first-order kinetics model line according to the equation: $\mathrm{V}=\mathrm{Vmax}(1-\exp (-\mathrm{k} \cdot \mathrm{t}))$; where $\mathrm{V}$ - the biogas volume produced in time $(\mathrm{t}), \mathrm{k}-$ the reaction rate constant and Vmax - the maximum gas volume.

However, the biogas production for co-digestion revealed the presence of two phases with different kinetics. The course of co-digestion confirmed the dependency of gas formation on 
the contribution of brewery spent grain in the mixture with sewage sludge. The trend of line of co-digestion consisted of two first-order kinetics models with the break point on the border on the phase I and phase II. The second phase in R2-R5 reactors started after 5-6 days of the experiment and could be accomplished with the degradation of lignocellulosic matter (specific BSG component). Such a complex structure required longer time to be converted to the monosaccharides, easily degradable by microorganisms. A similar curve shapes were obtained by Bernat et al. (2008) during mesophilic fermentation of sewage sludge and oil wastes. The trend line also consisted of two first-order kinetic models with the break point. This was caused by the use of oil wastes as a co-substrate and the inhibition of the process by VFA. In order to describe the cumulative biogas production phases in the co-fermentation process, detailed kinetics studies should be performed.

\section{CONCLUSIONS}

The results indicate that the measured additions of BSG/MBSG as a co-substrate for the thermophilic anaerobic digestion of sewage sludge enhanced both the biogas/methane potential and the production rate. Two phases of biogas production occurred while conducting co-digestion of BSG/MBSG and SS. The second phase is most likely accomplished with degradation of complex lignocellulosic compounds. No influence of BSG milling on the co-digestion effectiveness was observed. A comparison of the own research results and the findings of other authors investigating the co-digestion process under thermophilic conditions indicates that the use of milled and nonmilled brewery spent grain as a co-substrate in the thermophilic co-digestion is recommended.

\section{REFERENCES}

1. Angelidaki I., Ahring B. 1993. Thermophilic anaerobic digestion of livestock waste: the effect of ammonia. Applied Microbiology and Biotechnology 38, 560-564.

2. Bernat K., Białowiec A., Wojnowska-Baryła I. 2008. Co-Fermentation of Sewage Sludge and Waste from Oil Production. Archives of Environmental Protection 34(3), 103-115

3. Diego-Díaz B., Duran A., Álvarez-García M.R, Fernández-Rodríguez J. 2019. New trends in physicochemical characterization of solid lignocellulosic waste in anaerobic digestion. Fuel 245, 240-246.

4. Hendriks A.T.W.M.; Zeeman G. 2009. Pretreatments to enhance the digestibility of lignocellulosic biomass. Bioresource Technology 100, 10-18.

5. Kainthala J., Kalamdhad A.S., Goud V.V. 2019. A review of enhanced biogas production from anaerobic digestion of lignocellulosic biomass by different enhancement techniques. Process Biochemistry 84, 81-90.

6. Kucharska K., Rybarczyk P., Hołowacz I., Łukajtis R., Glinka M., Kamiński M. 2018. Pretreatment of Lignocellulosic Materials as Substrates for Fermentation Processes. Molecules 23, 2937.

7. Lebiocka M., Montusiewicz A., Bis M. 2018. Influence of milling on the effects of co - digestion of brewery spent grain and sewage sludge. Water supply and wastewater disposal. 94-101.

8. Madison M.J., Coward-Kelly G., Liang C., Nazmul Karim M., Falls M., Holtzapple M.T. 2017. Mechanical pretreatment of biomass e Part I: Acoustic and hydrodynamic cavitation. Biomass and Bioenergy 98, 135-141.

9. Montusiewicz A., Pawłowska M. 2017. Pretreatments to enhance the digestibility of recalcitrant waste - current trends. Advances in Renewable Energy Research. Taylor\&Francis Group, London, UK.

10. Mussatto S.I., Dragone G., Roberto I.C. 2006. Brewers' spent grain: generation, characteristics and potential applications. Journal of Cereal Science 43, 1-14.

11. Neshat S.A., Mohammadi M., Najafpour G.D., Lahijani P. 2017. Anaerobic co-digestion of animal manures and lignocellulosic residues as a potent approach for sustainable biogas production. Renewable and Sustainable Energy Reviews 79, 308-322.

12. Niemi P., Faulds C.B., Sibakov J., Holopainen U., Poutanen K., Buchert J. 2012. Effect of a milling pre-treatment on the enzymatic hydrolysis of carbohydrates in brewer's spent grain. Bioresource Technology 116,155-160.

13. Outeiriño D., Costa-Trigo I., de Souza Oliveira R.P., Guerra N.P., Domínguez J.M. 2019. A novel approach to the biorefinery of brewery spent grain. Process Biochemistry 85, 135-142.

14. Ravindran R., Jaiswal S., Abu-Ghannama N., Jaiswal A.K. 2018. A comparative analysis of pretreatment strategies on the properties and hydrolysis of brewers' spent grain. Bioresource Technology 248, 272-279.

15. Rodriguez C., Alaswad A., El-Hassan Z., Olabi A.G. 2017. Mechanical pretreatment of waste paper for biogas production, Waste Management 68, 157-164. 
16. Santos M., Jimenez J.J, Bartolome B., GomezCordoves C., del Nozal M.J. 2003. Variability of brewer's spent grain within a brewery. Food Chemistry $80,17-21$.

17. Sežun M., Grilc V., Zupančič G.D., Marinšek Logar R. 2011. Anaerobic Digestion of Brewery Spent Grain in a Semi-Continuous Bioreactor: Inhibition by Phenolic Degradation Products. Acta Chimica Slovenica 58(1), 158-66.
18. Siqueros E., Lamidi R.O., Pathare P.B., Wang Y., Roskilly A.P. 2019. Energy Recovery from Brewery Waste: experimental and modellig perspectives. Energy Procedia 161, 24-31.

19. Wang X., Duan X., Chen J., Fang K., Feng L., Yan Y., Zhou Q. 2016. Enhancing anaerobic digestion of waste activated sludge by pretreatment: effect of volatile to total solids. Environmental Technology 37(12), 1520-1529. 